\title{
Are we reaching the end of the petrol consumption? Will fossil fuels survive in an era of energy savings and environmental protection?
}

\author{
Nuno Domingues* \\ Isel-Adem, Rua Conselheiro Emídio Navarro, 1, 1959-007 Lisboa, Portugal
}

\section{Article Info}

\author{
*Corresponding author: \\ Nuno Domingues \\ Isel-Adem, \\ Rua Conselheiro Emídio Navarro \\ 1, 1959-007 Lisbon \\ Portugal \\ E-mail: nndomingues@gmail.com
}

Received: August 13, 2018

Accepted: August 21, 2018

Published: August 26, 2018

\section{Citation: Domingues N. Are we reaching the end of the petrol consumption? Will fossil fuels survive in an era of energy savings and environmental protection?. Int J Petrochem Res. 2018; 2(2): 165-171. doi: 10.18689/ijpr-1000129}

Copyright: () 2018 The Author(s). This work is licensed under a Creative Commons Attribution 4.0 International License, which permits unrestricted use, distribution, and reproduction in any medium, provided the original work is properly cited.

Published by Madridge Publishers

\begin{abstract}
Around the world there is an increase demand on renewable energies. The care for the environment and quality of life has highlighted the concerns for the world that our children inheritance. On the other side, there is still the inertia of keeping the BAU on energy consumption to maintain our level of life.

Along the past decades, the transport has been identified has the major pollution sector. Petrol based engines are fully optimized and the electronics associated don't have a role on the system efficiency anymore. Thereby, other solutions such as electrification and fuel cells are on the table to phase out petrol based engines.

Isolated islands of energy consumption where the electricity is not available (such as rural areas) or where they were very expensive (such as low energy intensive, welling and irrigation), used to be feed by diesel. With decentralized generation at affordable prices and better efficiencies, the paradigm is changing for a cleaner and low noise alternative.

District heating using fuel, coal and diesel are being substituted by solar, geothermal and electric heat pumps systems.

The present paper presents, discusses and reflects on the alternatives of the petrol and fossil fuel consumption paradigm.
\end{abstract}

Keywords: Fossil fuel, energy savings, energy efficiency, energy transitions, low carbon

\section{Introduction}

For some time and on their own pace, several Countries the energy efficiency systems are increasing and the primary energy sources are moving away from environmental impact. Equipment, appliances and processes experienced technological improvements that surplus the natural efficiency path. Following several people ideas, academic studies, ENGO pressure and political guidelines, the environmental goal in most Countries consists more and more on reducing energy demand and on reducing carbon emissions. Among various measures to achieve these objectives, several European countries have adopted taxes: carbon/energy, resource use, resource rents, for example. Our demand for energy keeps growing. Analysts forecast our energy demand in 2050 will be $30-40 \%$ higher than today, even assuming we become much more energy-efficient. Increases on this scale are not unprecedented. Over the past 30 years, worldwide energy demand has more than doubled. The need for low carbon energy transitions is driven by rapidly growing energy demand, as well as environmental concerns like climate change, peak oil, natural resource depletion and air pollution. A good way to make the transition is to leave the agents 
(mainly the consumer) the choice. In order for agents to make conscious decisions, the markets must give good information, including the full cost of the products. Subsidies therefore tend to take the form of price controls where the provision of a good or service is priced at a level below the full cost of supplying it. This had happened in Portugal with fossil power plants, having impacts on the allocation of resources (comparable with explicit subsidies) and having effects on public finances (significantly different from explicit subsidies). Putting an end to environmentally harmful fiscal loopholes can also contribute greatly to raise revenues and reduce budget deficits.

Portugal has a high consumption of oil, due essentially to three reasons:

- $\quad$ Absence of internal production capacity for oil and natural gas. Portugal has the capacity to produce only 14 percent of the energy you need. It is the thirteenth country (of the Fifteen) in terms of energy autonomy, far from the situation in Denmark, the United Kingdom or the Netherlands, countries that are "rich" in oil and / or natural gas;

- Greater energy intensity. Portugal is, along with Finland, the country with the highest energy intensity in the European Union of the Fifteen, that is, the country that incorporates the highest final energy consumption (measured in Tep) to produce an internal product unit (GDP). This fact is aggravated by the fact that energy intensity in Portugal is growing at an annual average of $0.9 \%$, while in the remaining EU15 countries (except Spain) there is a trend towards decreasing energy intensity;

- Greater energy dependence on oil. Oil accounts for about 64 percent of primary energy consumption in Portugal; in this ratio, our country is only surpassed by Luxembourg. Even if we considered the aggregate dependence on oil and natural gas, Portugal's position would remain rather unfavorable in the context of the Europe of the Fifteen.

In this context, consideration of other fossil fuels, such as coal, does not significantly alter Portugal's relative position in terms of dependence on this type of fuel. The impact of the dependence of Petroleum on the energy bill follows a similar evolution to that of natural gas due to the latter's mechanism of formation and the substitutability between these fuels in countries with a relatively large electricity generation portfolio.

Since it is not possible to act on a structural factor such as the national production capacity, attention must be focused on reducing energy intensity and dependence on oil, taking into account four additional criteria:

- impact on the energy bill (external);

- environmental impact;

- socioeconomic impact;

- impact on science and innovation;

- impact on the State Budget.

In order to make the Program actionable, the priorities for action were structured in four sectors: energy, transport, industry, and household consumption and services.
The energy practices and policies in the areas in which Portugal presents a greater potential to be applied are:

- Dependence on oil in the electricity generation sector (references: Austria, Sweden, Finland, France, Germany and Denmark). The solution found by the reference countries focuses mainly on the adoption of technologies associated with fuels other than oil. Of note are the increased use of water technology in Austria and Sweden and the increased use of wind, biomass and solar energy in Finland and Denmark as a complement to natural gas. Denmark's choice of natural gas and coal, in the absence of hydro and nuclear technology, is also an alternative to reduce dependence on oil. In addition, the adoption of nuclear technology has contributed to less dependence on oil in the countries that have adopted it, but it is nevertheless true that this technology raises a number of environmental and social issues

- Energy intensity of the transport sector (references: Italy, Germany, Austria, France and Spain). There is a wide range of measures adopted by the reference countries. However, it is important to note that a significant proportion of these measures are current practice in one form or another in most European Union countries, including Portugal. The countries of reference analyzed have developed four main lines of action: (1) Fiscal measures and subsidies to encourage a more efficient fleet; (2) Fuel tax applied in order to encourage the consumption of biofuels; (3) Adoption of integrated plans to encourage the use of public transport; and (4) Adoption of a network of road and rail infrastructures to improve the efficiency of passenger and freight transport, including the creation of logistics platforms and inter modality;

- Energy intensity of the industrial sector (references: Denmark, Germany and Ireland). In market economies, it is observed that the industrial sector itself seeks to become more efficient in order to guarantee its competitiveness. Nevertheless, there is still a need to develop incentive programs for the reduction of the energy intensity of the industry, mainly in activities that are the basis for the fastest growth of the economy, for example by concluding of energy audits and supporting up to 30 per cent of investment in energy intensity reduction projects;

- Dependence on oil (and natural gas) in the industrial sector (references: Finland, Sweden and Austria). The key performance factors of the reference countries are the use of renewable energy in industrial plants to meet their energy needs, including through the high use of biomass. In practice, cogeneration plants are built for the production of electricity and heat necessary for industrial processes, and the Governments of the reference countries have developed incentive programs for this purpose;

- Dependence on oil in the domestic sector and services Buildings (references: Spain and Greece). For domestic consumption, the reasons for less dependence on oil in the countries of reference are, for example, the use of solar thermal technology and energy efficiency regulations for buildings, which air conditioning. 
The analysis of the different European countries, in particular the reference countries, does indeed identify the greatest opportunities for improvement for our country. Although not all levers offer the same potential, it is clear that it should be possible to reduce energy intensity and dependence on oil in the various sectors of activity. The comparative analysis of the energy bills of the reference countries allows us to conclude that this objective can be achieved without increasing - on the contrary - the energy bill of Portugal.

- Possibility of reducing energy intensity and dependence on oil in different sectors. The industrial sector shows the greatest potential for improvement: it would be possible to reduce Portugal's total oil bill by around 40 percent if levels of intensity and dependence in this sector were reached, equal to the average of the reference countries. However, it is necessary to take into account the nature of the Portuguese industrial fabric more energy-dependent and more focused on value chain activities that generate relatively less added value, making it extremely difficult to approach European benchmarks. The dependence of electricity production on oil translates into a difference from the best practices corresponding to about 16 percent of the current oil bill. Among the other levers, the energy intensity of transport and the dependence on domestic consumption are additional opportunities to reduce the invoice, with the differentials of each of these two levers relative to the countries of reference of about 10 percent of the current invoice;

- Opportunity to reduce energy bills. Although they display smaller (relatively speaking) oil bills, most of the 10 reference countries analyzed also benefit from a lower energy bill than the Portuguese one. These data suggest that Portugal should aim to reduce its oil bill without increasing its energy bill.

\section{Alternatives to fossil fuel}

The International Energy Agency [1] highlights that only three of twenty-six low carbon innovation areas - solar PV and onshore wind, energy storage and electric vehicles (EV) - are mature, commercially competitive and on track to deliver their share of the climate objectives set out at the 2015 Paris Climate Conference. It is unlikely we can squeeze more out of these three technology areas than is currently projected. Solar PV and onshore wind are intermittent, so need to be used in conjunction with energy storage or other forms of power generation. The high-energy-density batteries that are used for both storage and EVs are causing concern around whether the supply of raw materials needed to manufacture them will be able to keep pace with their rapid uptake.

The World Economic Forum's latest white paper [2] proposes some bold ideas to significantly accelerate sustainable energy innovation and support the uptake of future energy sources.

Energy transitions are shifts from a country's economic activities based on one energy source to an economy based (partially) on another energy source. Fouquet and Pearson (2012) find that energy transitions are complex and rare events that have often taken place over very long period of time, such as decades or centuries. Several energy transitions have occurred in history [3]:

- the energy transition from manpower and animal power to traditional biomass (such as fuel wood, crop residues and dung)

- the energy transition from traditional biomass to coal (ca 1860),

- the energy transition from coal to oil (ca 1880)

- the energy transition from oil to natural gas (ca 1900)

- the energy transition from natural gas to electricity and heat (ca 1900-10)

- the large-scale commercial introduction of nuclear (ca 1965)

- the large-scale commercial introduction of renewable energy and large hydropower.

Bashmakov's three laws of energy transitions suggest the following:

- Energy transitions are often driven by changing energy costs in relation to income (the predominant energy form becomes too expensive).

- Energy transitions are often driven by improving energy quality (eg higher energy efficiency like electricity in comparison to fuel wood).

- Energy transitions are often driven by growing energy productivity (eg more industrial output can be obtained).

Low carbon energy transitions are here defined as shifts from a country's economic activities based on fossil fuels to an economy based (partially) on renewable and low carbon energy. This means that substitutions take place from fossil fuel-based technologies to low carbon technologies. Such transitions can take place in every sector of a country's or a region's economy. Observations from history have shown that most energy transitions were rather slow, often lasting more than a century [10]. [12] argues that historic energy transitions took about 80 to 130 years to fully happen. Faced by a changing climate and fossil fuel depletion many scholars suggest that a low carbon energy transition needs to be more rapid. [12] and [11] note that low carbon innovation, policies and financing need to be more persistent, continuous and balanced on a national and global level. They suggest that current policy frameworks are insufficient and need to be changed for enabling a low carbon energy transition.

To find alternatives or complements to fossil energies, there are some criteria for the evaluation of alternatives, the following being the most relevant:

Cost of Capital - In a period of intense competition for savings, accelerated by the aging of populations in developed countries, investments in the energy base will be in competition with investments in new technologies and their applications that offer greater prospects for future growth; then the renewal of the energy system must select combinations that minimize capital costs without impeding other requirements; 
Resource Abundance / Energy Density - the approach of peak oil production will put the demand for other primary energy sources on the agenda, with those that are more abundant and have a high "energy density" naturally benefiting;

Energy Efficiency - the need to reduce the intensity of use of fossil fuels, especially those with higher energy density, point to the incessant search for technological solutions that allow greater efficiency in the energy transformations that have these resources as a base;

Environmental Sustainability - the risks associated with poorly understood climate change point to greater attention to energy solutions with the highest pollution risk - in particular in terms of greenhouse gases - and to the search for technological solutions that seek to limit these impacts;

Digital Reliability - Increasingly organized and networked economies working on the basis of on-line telecommunications / telematics systems need to have an electricity supply with the least possible risk of interruptions and quality changes, given the disastrous impact such events can Tue;

Facility Security - in a world marked by the emergence of largescale terrorist phenomena, the vulnerability of energy facilities, particularly associated with risks of massive destruction of human lives, and the contribution of energy solutions facilitating nuclear proliferation have become in key criteria to evaluate which solutions may be most sought in the future.

\section{The role of Biodiesel}

The petrol and diesel fuel system already exists and works very well. Creating a system that eliminates gasoline and diesel fuel system instead of building a system on this would throw away an important ally. Therefore, biodiesel may play a relevant role in the future. The implementation of a system for the processing and recovery of vegetable oils used for their transformation into Biodiesel may bring the following environmental, economic and social benefits in relation to the use of fossil fuel for the production of diesel. Reducing $\mathrm{CO}_{2}$ emissions, aromatic compounds, particulates, benzenes and carcinogenic compounds, reducing imports of crude oil for processing and job creation are some of the advantages mentioned. The most obvious benefits will be the reduction of $\mathrm{CO}_{2}$ emissions which has been accounted for since 2005 with the new European Greenhouse Gas Emissions Directive and corresponding penalties for non-compliant member states. In order to assess the impact of using biodiesel to reduce $\mathrm{CO}_{2}$ emissions, the following baseline data should be taken into account: - Each tonne of $\mathrm{CO}_{2}$ emitted will be fined $€ 17.7$ (source: European Commission website www.eur.eu). - Estimates of the possible total collection of used vegetable oils point to the possibility of collecting 50,000 tonnes of vegetable oils from the 200,000 tonnes sold for catering and domestic use. - The valorisation of vegetable oil in biodiesel has a conversion factor of 1 to 1 with a also recoverable by-product of glycerin and fertilizer. - In the process of transterification of 50,000 tons, 50,000 tons of biodiesel, 5000 tons of glycerin and 5000 tons of fertilizer are generated. - The $\mathrm{CO}_{2}$ emission reduction factor when replacing $1 \mathrm{~kg}$ of fossil fuel with biodiesel is between $2.4 \mathrm{~kg}$ and $3.2 \mathrm{~kg}$. (Based on studies by the NREL and the US Department of
Energy after tests on vehicles using biodiesel blends to $20 \%$ and $30 \%)$. Using these data for Portugal, with the full use of the collected vegetable oil, it was expected: - a value of 120,000 to 160,000 tonnes of $\mathrm{CO}_{2}$ - a direct financial benefit in terms of reducing emissions from $€ 2,124,000$ to $€ 2,832,000$, taking into account the European rate of $€ 17.7$ per tonne, or roughly $€ 0.05$ per litre of biodiesel, which is equivalent to $€ 2,500.000 € /$ year. These values have not been verified, although the integration of biodiesel has been $5 \%$ and not only $3 \%$. However, the solution of small-scale equipment for the recovery of waste from producers, placing the product valued for burning in municipal fleets or other fleets of vehicles, still appears to be very advantageous for the following reasons: - The use of alternative fuels was mandatory for municipal vehicle fleets in 2006. - The objectives of the Directive adopted in terms of emission reduction points to $5 \%$ of biofuels in place of diesel was in 2005. - Creation of jobs and consequent discounts for social security and reduction of the unemployment rate. The transformation of 50,000 tons of waste involves the manufacturing (in national territory with national labour) of 200 production equipments with capacity for 1000 litres day. Each equipment involves the creation of 3 to 4 jobs for the collection, operation of equipment, quality control, administrative and commercial support and subsequent distribution of the product obtained. That is, 1 equipment 1 tonne day, 240 tons year justifies the existence of 3.5 full-time jobs. For the total of 200 equipment installed and to produce in full we get 700 full-time jobs. The 50,000 tons of biodiesel replace an equal number of tons of fossil fuel. So we get an amount of 250,000 barrels of crude from imports less on the balance of transactions with advantage to the Country. Also none of this came to fruition. for Portugal is also an opportunity to assert itself as capable of producing its own technology and to develop some product with the capacities that it has at its disposal and with the contributions of the national researchers technology-environment dialects assume multiple combinations, conditioned to the capacity of economic feasibility of the contributions of $R \& D$ in the identification of new processes to produce energy. The region richest in reserves - the Persian Gulf region - has difficulty in endogenously generating financial resources to increase the production that these reserves would allow, and the institutional framework of oil exploration that it has adopted - a state monopoly of companies - raising funds by other means. The concentration of reserves in what is one of the most unstable regions of the globe may, in turn, introduce elements of volatility in the price of hydrocarbons. Unconventional forms of oil, of which there are very significant reserves, consume a large amount of energy to be exploited, energy which in most cases has to be sought in conventional ways. These confirmed processes will trigger strong competition for the control of oil and gas resources on a global scale and enhance the role of Russia and the exUSSUR space in supplying developed countries.

\section{The role of hydrogen}

For some authors, hydrogen could be the future of green energy and has the potential to decarbonise electricity generation, transport and heat. That's because when produced by electrolysis - using electricity to split water $\left(\mathrm{H}_{2} \mathrm{O}\right)$ into hydrogen and oxygen - hydrogen does not produce any 
pollutants. In transportation, fuel cell electric vehicles have a longer range, a much faster refuelling time and require few behavioural changes. Hydrogen can also be used to households heating, blended with natural gas or burned on its own. The existing gas infrastructure could be used to transport it, which would avoid the grid costs associated with greater electrification of heat. Once produced, hydrogen could also act as both a short and long-term energy store. Figure 1 shows the schematic of the energy transition with hydrogen [4].

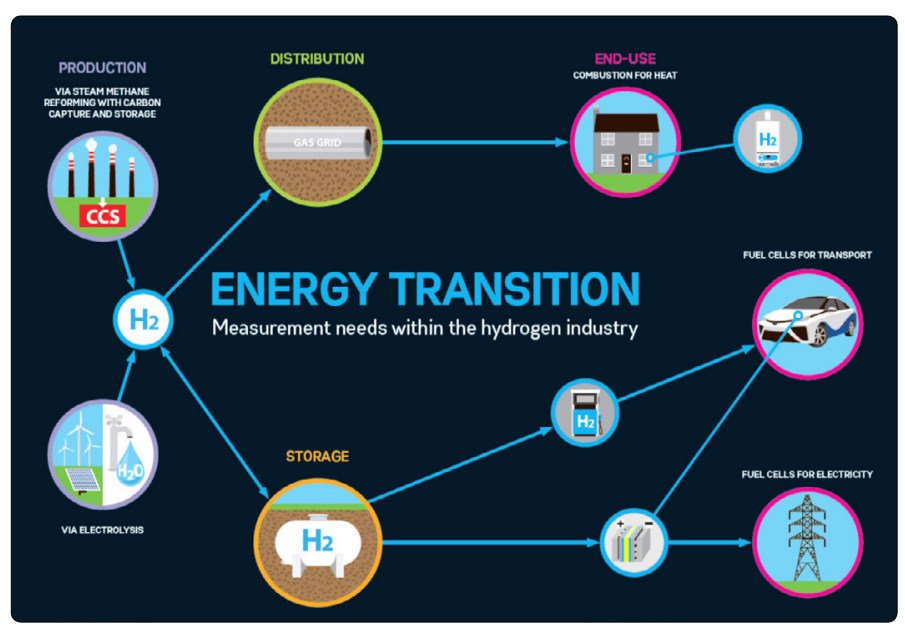

Figure 1. Energy transition with hydrogen

This philosophy has some research challenges. Currently, almost all of global hydrogen (96\%) is produced by reforming methane $\left(\mathrm{CH}_{4}\right)$, a process which ultimately produces carbon dioxide. To be sustainable, this production method would need to be deployed with carbon capture and storage, which is itself in need of further development. Electrolysis produces no carbon emissions. Yet the amount of hydrogen that can be produced using this method depends on the cost and availability of electricity from renewable sources. Concerns about the safety of using hydrogen also need to be addressed. [4] noted two priority safety issues when transporting hydrogen in the grid and combusting it for heat. When hydrogen is combusted, one can't see the flame, so there needs to detect whether it is lit. Hydrogen would be transported and stored at high pressures, so one needs to find an odorant that works with hydrogen so that people can detect leaks.

Other author defend that a hydrogen economy doesn't make sense. The large amount of energy required to isolate hydrogen from natural compounds (water, natural gas, biomass), package the light gas by compression or liquefaction, transfer the energy carrier to the user, plus the energy lost when it is converted to useful electricity with fuel cells, leaves around $25 \%$ for practical use - an unacceptable value to run an economy in a sustainable future. Only niche applications like submarines and spacecraft might use hydrogen. More energy is needed to isolate hydrogen from natural compounds than can ever be recovered from its use. Therefore, making the new chemical energy carrier form natural gas would not make sense, as it would increase the gas consumption and the emission of $\mathrm{CO}_{2}$. Instead, the dwindling fossil fuel reserves must be replaced by energy from renewable sources [5]. Also, the advantages of hydrogen (non-toxic, burns to water, abundance of hydrogen in the Universe, etc.) are misleading, because the production of hydrogen depends on the availability of energy and water, both of which are increasingly rare and may become political issues, as much as oil and natural gas are today. Also, hydrogen is not a source of energy, but only a carrier of energy. As a carrier, it plays a role similar to that of water in a hydraulic heating system or electrons in a copper wire. When delivering hydrogen, whether by truck or pipeline, the energy costs are several times that for established energy carriers like natural gas or gasoline. Even the most efficient fuel cells cannot recover these losses, Bossel found. For comparison, the "wind-to-wheel" efficiency is at least three times greater for electric cars than for hydrogen fuel cell vehicles. Finally, there is the problem of storage. When storing liquid hydrogen, some gas must be allowed to evaporate for safety reasons, meaning that after two weeks a car would lose half of its fuel even when not being driven.

\section{The role of CCS}

Carbon capture and sequestrion can have a key role on maintaining the interest in exploring oil. Figure 2.3 shows how they are linked (WRI, 2007).

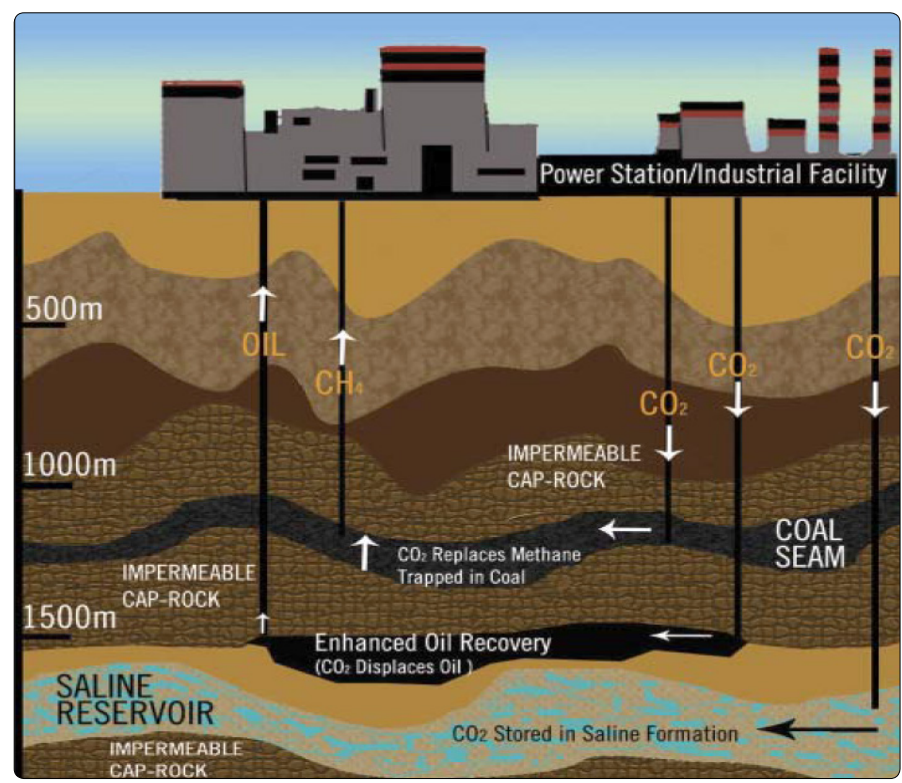

Figure 2.3. CCS and Oil exploration

\section{Energy islands}

We still need to develop studies that study a micro and mini grid in Medium Voltage with micro generators, loads and energy storage devices, with a single point of connection to the network. The development of distributed generation has been pointed out as one of the main ways to achieve the objectives of the current European Energy Policy: security of supply, competitive electricity prices and reduction of environmental impacts. However, they lack the work of designing, developing and implementing a model of a Medium Voltage micro and mini grid in order to study its dynamic behaviour in different operating modes (isolated or interconnected), different load levels, different production technologies, different energy storage solutions, with and 
without energy single directionality. There is also a need to study and develop an energy management and control system for micro and mini grid, according to a defined strategy. Finally, there is a need to monitor the performance of micro and mini grid by developing a computer tool and defining performance indicators.

\section{Spatial planning and Regional level}

There are some examples, such as in Lisbon the main city in Portugal. Lisbon will be European Green Capital 2020, bringing great significance and responsibility. First, the recognition of a political strategy that began in 2007 remains today, which aims to take care of the sustainability of the city. That meant a concrete policy in various areas: green areas (in the municipal master plan 2012 had a large increase with a doubling to 400 hectares of green spaces); return of public space to citizens; attention to drainage of flood waters (with the approval of a drainage plan is in the execution phase) and the focus on sustainable mobility (with priority to public transport). The electric mobility is not considered as a major driven. In Lisbon, the Praça de Espanha redevelopment project will move forward, turning an arid zone of motor traffic in a large area for public enjoyment. From September on it will start coming new buses running on Diesel. In total will be more than 200, about one-third of the current fleet of the company. New buses are more environmentally sustainable and significantly increase the supply capacity that will reduce car emissions and the same time improve competitiveness and quality of life. In a second phase, remove those who are now older buses, more polluting and that they should no longer be of service. Carris Bus Company will be enhanced, meaning less waiting time between buses, more routes, increased service coverage, plus transportation to the weekend and at night. The whole area of Alcântara, Ajuda, Belém, Beato and Marvila will be strengthened. The local authority will make an investment in the electric mobility network. Lisbon had a very comprehensive network that went to many places in the city. It was a big mistake to have destroyed this extraordinary infrastructure. The Lisbon municipality is working with neighbouring municipalities to also extend the electrical network. Today, one-half to twothirds of the active population that is in Lisbon (working or studying) comes from out of town.

The return of public electric mobility will involve a significant investment in the acquisition of rolling stock, but has a dual capacity: medium heavy at getting carry many people per hour with quality and efficiency, if the channels are well designed, and at the same time it is more environmentally friendly. However, this paradigm will not put away fossil fuels since there will be an increase of electricity consumption by the peak hours that will be produced by natural gas.

The Lisbon Metropolitan Area (as well as Oporto city) assumed that the issue of mobility, environmental sustainability and transport should be a major priority of the next Community Support Framework from the government. Obviously tourism brings great value in employment, openness to the world, international recognition, and one must take advantage of this dimension. The cause of sustainability is central to all communities. However, it is demanding to have to adapt the city's systems to increased tourism and increased employment that tourism generates. It is a very demanding challenge, both in waste and in transport. Moreover, the household and the accommodation energy consumption will increase based on natural gas (directly as primary energy or indirectly in the electricity form). This challenge is already very present today.

Portugal is reactivating the abandoned Beja Airport with two parallel tracks $3 \mathrm{~km}$ each, with a capacity equivalent to two terminals of Portela, is part of a country with a lack of airport capacity in Lisbon and the Algarve. The Beja Airport is a project of the German Luftwaffe, when they wanted to install a strategic military base within NATO and studied the land access to the airport that they would build. The Luftwaffe and its planning for the Beja Airport, came to the conclusion which the airport would have to get to $110 / 150 \mathrm{~km}$ from Faro and $110 / 160 \mathrm{~km}$ from Lisbon (which in turn is the same distance from Monte Real / Leiria, which in turn is in the same range away from Ovar base, which is $100 \mathrm{Km}$ from Pedras Rubras). And this is at $150 \mathrm{~km}$ of Vigo-Peinador, which is also a similar distance Santiago-Lavacolla. The Germans devised Beja as part of a network. But other criteria on which it supported to materialize the airport was the railway line, built by the [8] British South \& South Eastern Railway and supplemented by the Portuguese State Railway Track in the XIX century. They looked at the immensity of the lines that have that route, interrupted here and there by a large radius curve, with a huge angle of low-flying, and concluded that it was in fact the railroad, enabling them, in case of war, quickly mobilize resources land to support their air base. Here is a teaching of integrated mobility heritage for Portugal from the Germans and the British. The Germans, offered a gigantic airport capacity that simultaneously solves the chronic problems of ability to Lisbon and Faro. The British, equipped a railroad that thanks to its characteristics and proximity to the airport is able to project its hinterland or area of influence for well over $150 \mathrm{~km}$ to the north [9], south and to the east to Extremadura Spanish (and in this case instrumental to the construction of the Euro-region of Peninsular Southwest). The Beja airport allows gain scale and integrates markets in a borderless Europe. This project will increase the fossil fuel consumption.

The Nordic countries, Denmark, Finland, Iceland, Norway and Sweden, are seen as global leaders in low carbon energy transitions. These countries have ambitious climate and energy policies in place, aiming to be fossil free by 2050 [6]. Iceland relies almost completely on geothermal energy for heating, including for district heating, and exclusively on hydropower and geothermal energy for electricity production [7]. Sweden relies heavily on hydropower and nuclear energy for electricity production and on biofuels for heating [10-14]. Denmark reduced its reliance on fossil fuels over time and increased its share of renewable energy, particularly wind energy and biofuels. Finland has a more varied energy portfolio, but today relies predominantly on nuclear energy, hydropower and biofuels [7]. While Iceland, Sweden, Denmark 
and Finland experienced a decline in the reliance on fossil fuels between the 1970s and the 1990s, Norway still depends a lot on oil even today [15]. Norway has access to abundant domestic oil resources. Nevertheless, more than $95 \%$ of the country's electricity came from hydropower in 2015 [7].

\section{Conclusion}

The energy consumption is getting more and more related to economics and market. Market based instruments have a key role to guide the market agents on their decisions. Thereby, their correct use can help to accomplish a desired goal and honour an international agreement. Also, the correct design and implementation is a strong guidance for sustainable consumption.

Countries need to scale up existing low-carbon technologies at a much faster rate, otherwise population growth will continue to outpace investment in renewables and fossil fuels will continue to dominate. However, one cannot keep asking for more from technologies that have proved successful to-date. Given the scale of the decarbonisation challenge, one needs to use many technological solutions in tandem with fossil fuels, with highlight to petrol.

The end of fossil fuels era is not reaching the end. Fossil fuel still has a key role to play in every Country.

\section{References}

1. IEA, 2017, Tracking Clean Energy Progress: 2017, available online http:// www.iea.org/etp/tracking2017/, last access on 13 ${ }^{\text {th }}$ of August of 2018.

2. WEF- World Economic Forum, White Paper, 2018, Accelerating Sustainable Energy Innovation, available online http://www3.weforum.org/docs/ Accelerating_sustainable_energy_innovation_2018.pdf, last access on $13^{\text {th }}$ of August of 2018.

3. Bashmakov I. Three laws of energy transitions. Energy Policy. 2007; 35(7): 3583-3594. doi: 10.1016/j.enpol.2006.12.023

4. European Communities publication. Taxation trends in the European Union, 2010; ISBN 978-92-79-15801-8.

5. NFL- National Physical Laboratory, 2018, Energy transition reports, available online http://www.npl.co.uk/energy-transition/, last access on $13^{\text {th }}$ of August of 2018.

6. Science $X, 2006$, Why a hydrogen economy doesn't make sense, available online https://phys.org/news/2006-12-hydrogen-economy-doesnt.html\#jCp, last access on $13^{\text {th }}$ of August of 2018.

7. Sovacool B. Contestation, contingency, and justice in the Nordic lowcarbon energy transition. Energy 451 Policy. 2017; 102(3): 569-582. doi: 10.1016/j.enpol.2016.12.045

8. IEA, 2018. Energy statistics. www.iea.org/statistics/, last access on $13^{\text {th }}$ of August of 2018

9. Araujo K. Low Carbon Energy Transitions: Turning Points in National Policy and Innovation. Oxford University Press, OxfordBossel, Ulf. "Does a Hydrogen Economy Make Sense?" Proceedings of the IEEE. 2007; 94(10).

10. European Environment Agency, Environmental taxes: recent developments in tools for integration. 2000, ISBN: 92-9167-261-0.

11. Foxon T. Energy and Economic Growth. Why we need a new pathway to prosperity. Routledge, Oxon, 2018.

12. Foxon T, Kohler J, Oughton C. Innovation for a Low Carbon Economy. Edward Elgar, Cheltenham, 2008.
13. Geels FW. Disruption and low-carbon system transformation: Progress and new challenges in socio technical transitions research and the MultiLevel Perspective. Energy Research \& Social Science. 2018; 37(3): 224-231. doi: 10.1016/j.erss.2017.10.010

14. Geels FW, Sovacool BK, Schwanen T, Sorrell S. The Socio-Technical Dynamics of Low-Carbon Transitions. Joule. 2017; 1(3): 463-479. doi: 10.1016/j.joule.2017.09.018

15. Smith S. Environmental taxes and competitiveness: an overview of issues. policy options, and research needs. OECD Papers, ISSN 16091914. 